2015

Effectiveness of helmets in preventing severe injuries in a setting with poorly enforced quality standards

junaid Ahmad Bhatti

Junaid A. Razzak

Rashid Jooma

Follow this and additional works at: https://ecommons.aku.edu/pakistan_fhs_mc_emerg_med

Part of the Emergency Medicine Commons, and the Neurosurgery Commons 
*Sunnybrook Health Sciences Centre, Toronto, Canada

junaid.bhatti@ices.on.ca 10.5339/jlghs.2015.itma.21

Junaid Ahmad Bhatti; Junaid A Razzak; Rashid Jooma, licensee Bloomsbury Qatar Foundation Journals. This is an open access article distributed under the terms of the Creative Commons Attribution license CC BY 4.0 , which permits unrestricted use, distribution and reproduction in any medium, provided the original work is properly cited.

\title{
Effectiveness of helmets in preventing severe injuries in a setting with poorly enforced quality standards
}

\author{
Junaid Ahmad Bhatti*; Junaid A Razzak; Rashid Jooma
}

Helmets save lives, yet many countries do not have laws about their quality assessment or how they should be worn. We assessed the effectiveness of helmet use in preventing injuries in such a setting.

The data were extracted from a large road traffic injury surveillance study in Karachi, Pakistan. We assessed the association of wearing helmets with several injury outcomes including deaths, injury severity (via New Injury Severity Score, NISS $\geq 9$ ) and moderate or severe injury (via Abbreviated Injury Score, AIS $\geq 2$ ) to head, face, or other regions of the body.

The data about helmet use was available for about 109,210 riders injured between January 2007 and December 2013. Only 6\% of riders wore helmets, whereas this proportion was less than one percent in pillion riders and women. The rates were also lower among those aged 18 years or younger ( $1 \%$ ) and those aged 18 to 25 years ( $4 \%$ ). About $2 \%$ of riders died; $34 \%$ had an injury to the head region, $30 \%$ to face, $1 \%$ to chest, $5 \%$ to abdominal, $46 \%$ to extremities, and $61 \%$ to external body regions. Likelihood of dying was low among helmet users (adjusted odds ratio [aOR] = 0.37, $95 \%$ confidence interval $[\mathrm{Cl}]=0.28$ to 0.50 ). Helmets reduced the likelihood of moderate to severe injuries to the head $(\mathrm{aOR}=0.68,95 \% \mathrm{Cl}=0.58$ to 0.80 ) but not to the face region $(\mathrm{aOR}=1.37,95 \% \mathrm{Cl}=$ 1.17 to 1.62). Helmet users also had severer injuries in other body regions except for chest injuries.

Helmets prevented deaths and severe head injuries but had limited effectiveness in preventing facial injuries in this setting with poor helmet use standards. More work is needed to understand the helmet wearing and rider behaviours in helmet users in this setting. 


\section{فعالية خوذات السلامة في منع الإصابات الحادة ببالمواقع ذات معايير الجودة المتدنية}

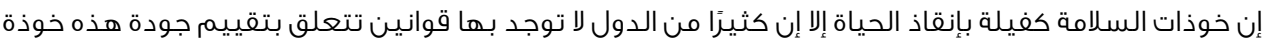

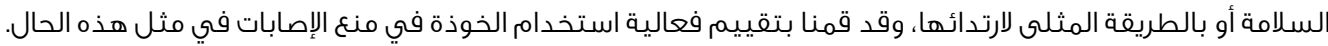

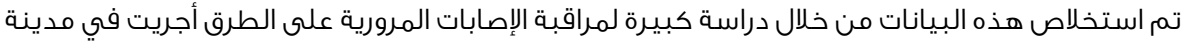

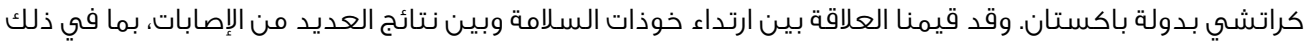

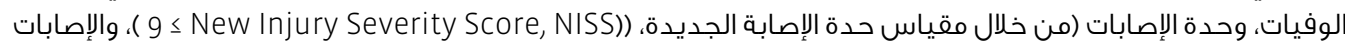
المتوسطة أو الحادة (من خلال المقياس الموجز للإصابة (Abbreviated Injury Score, AIS ـ 2 2)) في الرأس، أو الوجه،

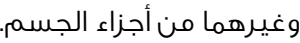

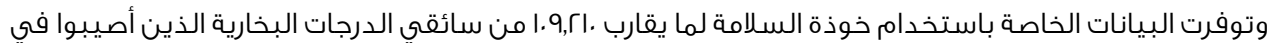

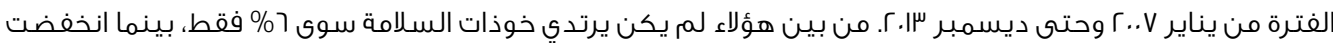

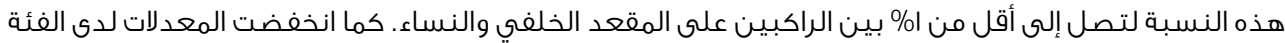

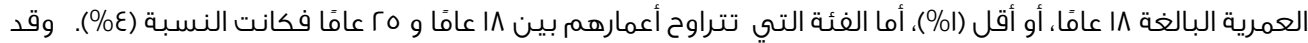

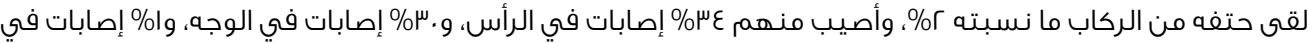

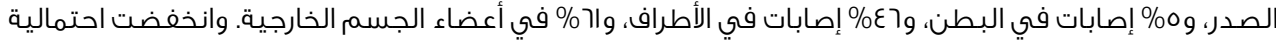

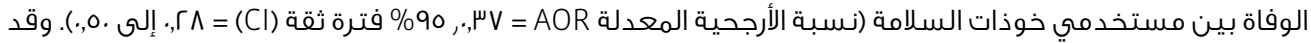

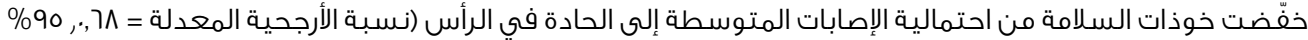

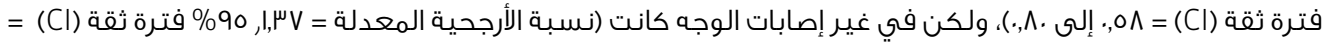

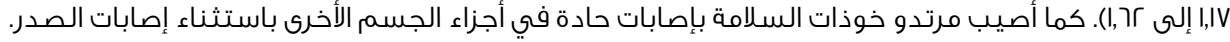

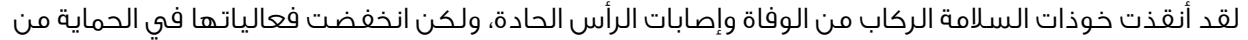

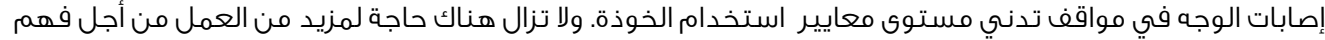
تعليمات ارتداء خوذة السلامة وسلوكيات الراكبين الذين يستخدمون الخوذة في مثل هذه المواقف. 